\title{
Varieties of responsibility: two problems of responsible innovation
}

\author{
Ibo van de Poel $^{1}$ (D) Martin Sand ${ }^{1}$ (D)
}

Received: 31 January 2018 / Accepted: 18 September 2018 / Published online: 29 September 2018

(c) The Author(s) 2018

\begin{abstract}
The notion of responsible innovation suggests that innovators carry additional responsibilities (to society, stakeholders, users) beyond those commonly suggested. In this paper, we will discuss the meaning of these novel responsibilities focusing on two philosophical problems of attributing such responsibilities to innovators. The first is the allocation of responsibilities to innovators. Innovation is a process that involves a multiplicity of agents and unpredictable, far-reaching causal chains from innovation to social impacts, which creates great uncertainty. A second problem is constituted by possible trade-offs between different kinds of responsibility. It is evident that attributing backward-looking responsibility for product failures diminishes the willingness to learn about such defects and to take forward-looking responsibility. We will argue that these problems can be overcome by elaborating what it is exactly that innovators are responsible for. In this manner, we will distinguish more clearly between holding responsible and taking responsibility. This opens a space for 'supererogatory' responsibilities. Second, we will argue that both innovation processes and outcomes can be objects of innovators' responsibility. Third, we will analyze different kinds of responsibility (blameworthiness, accountability, liability, obligation and virtue) and show that the functions of their attribution are not necessarily contradictory. Based on this conceptual refinement, we will argue that accountability, responsibility-as-virtue and the willingness to take responsibility are crucial for responsible innovation.
\end{abstract}

Keywords Responsible innovation · Responsibility · Ethics · Virtue · Accountability $\cdot$ Engineering $\cdot$ Technology

$\triangle$ Ibo van de Poel

i.r.vandepoel@tudelft.nl

Martin Sand

m.sand@tudelft.nl

1 Department of Values, Technology and Innovation, School of Technology, Policy and Management, TU Delft, Jaffalaan 5, 2628 BX Delft, The Netherlands 


\section{Introduction}

In recent years, the notion of responsible innovation has come into vogue. It reflects the idea that research and innovation should be better aligned with the values, needs and expectations of society (European Commission 2014). Already during the early phases of technological research and development, innovators should anticipate potential uses and societal consequences, risks and benefits of technologies and pro-actively aim to contribute with research and innovation to important moral values and societal challenges (Stilgoe et al. 2013; Van den Hoven 2013; European Commission 2017; Owen et al. 2013). Innovation processes should also be inclusive by addressing a range of potential societal and moral concerns and by including all relevant stakeholders (European Commission 2012; Owen et al. 2013; Stilgoe et al. 2013). Moreover, innovation processes should become responsive to social needs and values. Responsible innovation is suggested to sensitize relevant actors regarding impacts of technology for society and encourage their reflection of possible moral issues (Owen et al. 2013; Stilgoe et al. 2013).

Responsible innovation implies the attribution of a range of new responsibilities to innovators. However, is it indeed reasonable and fair to expect innovators to assume such responsibilities? Moreover, if we assume that those novel responsibilities are intended to transform innovation processes to the better, is their attribution conducive to this purpose or rather counterproductive? As pointed out in the Directorate-General for Research and Innovation EU (2013: p. 55): "Strictly speaking it is not the innovation itself that is responsible. Responsible innovation is a truncated and indirect way of referring to contexts in which people are the appropriate subjects of responsibility claims and who either feel responsible, or who can be held or can be made responsible. 'Responsible innovation' can thus be used to refer in the realm of innovation to whatever invites, accommodates, stimulates, enhances, fosters, implies or incentivizes responsible action and the mental states that are typically associated with it". ${ }^{1}$

In this paper, we will use the term 'innovators' for agents that are involved in, and shape (consciously or unconsciously) the innovation process and the resulting innovative products (or services or systems). This definition refers to a variety of professionals such as scientists, engineers, marketers or CEOs. Our focus will be individual rather than collective agents such as companies or research labs. The attribution of responsibility to collective agents raises additional, intricate issues about collective agency that are beyond the scope of this article. While individuals might not be the only addressees of responsibility, they clearly form the nucleus of responsibility debates. This justifies focusing on individuals as a starting point to discuss responsible innovation.

Despite the growing literature on responsible innovation and the rich philosophical debate about responsibility, the potential for mutual learning by studying the crosslinks of those fields is severely underexplored (notable exceptions include: Grinbaum and Groves 2013; Pellé and Reber 2015). We will start with a brief discussion of the notion of responsible innovation. Then, we will introduce different meanings of responsibility

\footnotetext{
1 Often 'responsible' in the term 'responsible innovation' seems to be used as a shorthand for 'morally desirable' and does not imply the attribution of moral agency, as is the case when we speak about 'responsible persons'. Innovation - either understood as a process or as a product ('an innovation') — does not possess moral agency (at least not in the traditional sense of that term).
} 
in order to establish a preliminary answer to the question which responsibilities should be attributed to innovators in the light of responsible innovation. Next, we will discuss two problems of attributing responsibility to innovators: (1) It would often be unfair to attribute responsibility to innovators because crucial conditions for responsibility are not fulfilled, and (2) attributing responsibility to innovators would sometimes be ineffective in making innovation more responsible.

\subsection{Responsible innovation: process and product dimension}

There is a number of definitions of 'responsible innovation'. ${ }^{2}$ Some of these definitions emphasize both the innovation process as well as the outcomes of that process, i.e. the innovations that are taken up by and embedded in society (where they result in certain social consequences), as objects of moral concern. An example is the following definition from René von Schomberg: "Responsible Research and Innovation is a transparent, interactive process by which societal actors and innovators become mutually responsive to each other with a view on the (ethical) acceptability, sustainability and societal desirability of the innovation process and its marketable products (in order to allow a proper embedding of scientific and technological advances in our society)" (Von Schomberg 2012: p. 50). We will refer to these aspects in the following as the product and the process dimension of responsible innovation.

Some definitions of responsible innovation mainly stress the process dimension of innovation. An example is the Rome Declaration on Responsible Research and Innovation which defines Responsible Research and Innovation (RRI) as "the on-going process of aligning research and innovation to the values, needs and expectations of society" (European Commission 2014). Another example is the influential framework for responsible innovation proposed by Owen et al. (2013) and Stilgoe et al. (2013). In their framework, the authors stress four dimensions of responsible innovation, namely:

- Anticipation Are the possible social consequences (risks and benefits) of innovations anticipated and fed back to the innovation process?

- Reflexivity Do the innovators reflect on the social goals, values, expectations and promises of their innovations and are they aware of their assumptions?

- Inclusion (or deliberation) Are all relevant stakeholders included in the process of innovation?

- Responsiveness Is the innovation process responsive to the needs, values and expectations of society and to new insights that arise during innovations' development and implementation into society?

These dimensions of responsible innovation are procedural in nature. They assume that responsible innovation is a process that should meet desirable attributes. Innovators are at least co-responsible to ensure that the innovation process meets those characteristics.

\footnotetext{
2 Below we only discuss some of the main definitions found in the literature on 'responsible innovation.' Other relevant definitions have been proposed in various EU projects. The EU has also proposed six keys to responsible innovation, namely engagement, gender equality, science education, open access, ethics, and governance (European Commission 2012). However, not all of these keys directly address the innovation process. Therefore, we do not discuss them in detail below.
} 
In addition to the process dimension, there is the product dimension of responsible innovation, which refers to the products (services, systems) as the result of the innovation process. Eventually, these products diffuse into society. As we have seen, this product dimension is mentioned in von Schomberg's definition. It is also present in the definition of responsible innovation advocated by van den Hoven (2013: p. 82): "Responsible Innovation is an activity or process which may give rise to previously unknown designs pertaining either to the physical world (e.g., designs of buildings and infrastructure), the conceptual world (e.g., conceptual frameworks, mathematics, logic, theory, software), the institutional world (social and legal institutions, procedures, and organization) or combinations of these, which-when implemented-expand the set of relevant feasible options regarding solving a set of moral problems." The idea expressed here is that innovations often try to meet different, potentially conflicting values. Safer cars for example are often heavier, implying more fuel consumption and decreased sustainability (Van Gorp 2005). Safety and sustainability are conflicting values in car design and create moral overload, i.e. the impossibility to meet various moral requirements at the same time (Van den Hoven et al. 2012). According to van den Hoven, responsible innovation means the overcoming of moral overload by innovation, i.e. by developing new options that resolve value conflicts. Van den Hoven's definition is exemplary in emphasizing the product dimension of innovation, which is another object of moral concern for innovators. We see that implementing the process criteria for responsible innovation does not guarantee that the resulting innovations (products, services, systems) will be responsible. Therefore, responsible innovation implies at least a twofold responsibility for innovators: first for the process of innovation and second for the products ('innovations'), the result of such processes.

\subsection{Different meanings of responsibility}

In its ordinary use the concept of responsibility is ambivalent. Hence, it is mandatory to first distinguish different meanings to see what types of responsibilities are ascribed to innovators in responsible innovation. ${ }^{3}$

First, it is noteworthy that the term 'responsibility' is sometimes used descriptively and sometimes normatively. Descriptive meanings of responsibility identify responsibility with cause (which is presumed in the term's application to effective, inanimate objects), or with someone's tasks or role in an organization or as realm of authority.

In the following, we will focus on the normative meanings of responsibility. The normative meanings of responsibility can be differentiated into two prime classes: the evaluation of an act or character trait in terms of praiseworthiness or blameworthiness, and the prescription in terms of an obligation to do something or to see to something, or to take care of something. Table 1 presents the 5 main normative meanings of responsibility that are distinguished in van de Poel et al. (2015: chapter 1), and which will be adopted for the following discussion.

\footnotetext{
3 Herbert Hart (1968) was probably the first to offer a taxonomy of responsibility; more recent taxonomies are presented for example in Vincent (2011), Davis (2012) and van de Poel et al. (2015).
} 
Table 1 Normative meanings of responsibility

\author{
Backward-looking \\ Responsibility-as-blameworthiness \\ Responsibility-as-accountability \\ Responsibility-as-liability \\ Forward-looking \\ Responsibility-as-obligation \\ Responsibility-as-virtue
}

A main distinction to be made is between backward-looking and forward-looking responsibility, also sometimes called historical and prospective responsibility (Cane 2002) or retrospective and prospective responsibility. Backward-looking responsibility refers to past actions and usually involves an evaluation of these actions and the attribution of blame or praise to the agent (Watson 2004b; Smith 2007). ${ }^{4}$ Backwardlooking responsibility attributions, however, rest on the prior identification of an agent as the 'instigator of an act', which is the accountability of an agent. Accountability means that an action, for which an agent is held responsible, 'belongs to' or is 'owned by' that agent. In order to correctly consider an agent as 'instigator of an act', the agent has to be free in a relevant sense, be able to form her own intentions and be aware and responsive to moral demands (moral agency). In the case of accountability for outcomes (rather than actions), we suggest a causal chain between the agent's action and an outcome. Apart from an ex post evaluation, accountability also has a prescriptive dimension as it presumes the ability and willingness to account for one's actions and to justify them to others (Watson 2004a). The reasonability of blame or praise for an action (and its outcomes) depends on the quality of justification and whether and how the previously outlined conditions are complied with. ${ }^{5}$

In addition to accountability and blame or praiseworthiness, a third important normative backward-looking meaning of responsibility is liability. Liability means the obligation to remedy a situation for which one is responsible or to compensate for damage (Andre 1983; Hart 1968). Liability as compensation is usually associated with undesirable outcomes, and hence with blame - rather than praiseworthiness. However, in the idea of deserving to be treated with dignity or to receive a prize we see the prevalence of a positive notion of liability as compensation.

In addition to these three backward-looking responsibilities, we distinguish two forward-looking types of responsibility. The first is responsibility as obligation, in particular the obligation to see to it that a certain state-of-affairs occurs (Goodin 1995). According to Goodin such responsibilities, "require certain activities of a selfsupervisory nature from A. The standard form of responsibility is that A see to it that

\footnotetext{
${ }^{4}$ For the sake of simplicity, we will neglect in the following that evaluations of people's responsibility do not necessarily lead to certain reactions to them. We will neglect the distinction between 'being' and 'being held' responsible (Watson 2004b; Smith 2007).

5 As Aristotle already pointed out, two types of excuses are particularly important when it comes to avoiding blameworthiness, namely ignorance, i.e. the inability to know the moral quality or outcomes of one's actions and coercion, the availability of reasonable alternatives (Aristotle, Nicomachean Ethics: book 3).
} 
$\mathrm{X}$. It is not enough that X occurs. A must also have 'seen to it' that X occurs. 'Seeing to it that $\mathrm{X}$ ' requires, minimally; that A satisfy himself that there is some process (mechanism or activity) at work whereby X will be brought about; that A check from time to time to make sure that that process is still at work, and is performing as expected; and that A take steps as necessary to alter or replace processes that no longer seem likely to bring about X" (Goodin 1995: p. 83). Such obligation-responsibilities may be further distinguished in the responsibility to avoid harm from occurring (which Cane (2002) calls protective responsibilities) and responsibility to do well (which Cane (2002) calls productive responsibilities).

In addition to responsibility-as-obligation, we further distinguish responsibility-asvirtue. Unlike the previously discussed kinds of responsibility, responsibility-as-virtue does not refer to actions (or outcomes) but rather to certain character traits of the agent. This can be exemplified with an agent's disposition to assume or to take responsibility and an awareness of a range of relevant normative demands. In the words of Garrath Williams: "There is an element of reliability and commitment, of carrying on with something over time. There is a dimension of initiative and judgement: the agent can be trusted with something and to exercise some degree of discretion. There is an obvious connection between the virtue and retrospective responsibility, in terms of mutual accountability. This involves a readiness to identify with and answer for past actions or omissions, and to make up for these where they have proved faulty. ... Clearly, the virtue is closely related to consciousness in fulfilling one's responsibilities. With some circularity, one might say that responsibility suggests an agent who lives up to her, or its, position within a division of responsibilities and within relations of mutual accountability" (Williams 2008: p. 459).

The philosophical literature on responsibility traditionally discussed the conditions for attributing accountability and blameworthiness to agents, and whether such attributions are still meaningful if determinism were true. As a consequence, these debates are focused on backward-looking responsibility for reprehensible actions or negative consequences. As Pellé and Reber (2015) rightly stress, it is also important for responsible innovation to pay attention to forward-looking responsibilities and to positive responsibilities.

The following diagram (Table 2) presents an overview of the distinctions introduced in the previous sections. As a preliminary result, we suggest four types of responsibilities attributable to innovators in the light of responsible innovation: forward-looking responsibility for both the process and product dimension of responsible innovation as well as backward-looking responsibility for both dimensions.

Table 2 The responsibility matrix of responsible innovation

\begin{tabular}{|c|c|c|}
\hline & Product & Process \\
\hline \multicolumn{3}{|l|}{$\begin{array}{l}\text { Backward-looking } \\
\text { responsibility }\end{array}$} \\
\hline $\begin{array}{l}\text { Forward-looking } \\
\text { responsibility }\end{array}$ & & \\
\hline
\end{tabular}




\section{Two problems of attributing responsibility to innovators}

We have argued that responsible innovation implies the attribution of four types of responsibility to innovators. In practice, however, such attribution raises two problems, which stem from two contrary motivations of responsibility attributions: fairness and efficiency.

A responsibility attribution is fair or appropriate, if an agent meets a number of conditions (like intentionality, free will, causality etc.). Below, we will argue that these conditions are rarely met in innovation processes.

We also want responsibility attributions to be effective. The attribution should stimulate desirable behavior and discourage undesirable behavior (Vargas 2013). These are central goals of responsible innovation. After all, the notion of responsible innovation was introduced with a view to steering innovations processes in socially and morally desirable directions (Von Schomberg 2012). The attributions of responsibility to innovators in the context of responsible innovations has been designed to make innovations more responsible. However, as we will argue later on, the attribution of certain kinds of responsibility to innovators can discourage rather than stimulate desirable behavior or the taking of responsibility. In particular, the attribution of blame or liability can discourage innovators to take forward-looking responsibility, which undermines a central purpose of responsible innovation. ${ }^{6}$

\subsection{Is it fair to attribute responsibility to innovators?}

In 1939, Einstein was one of the scientists who signed a letter to President Roosevelt warning of the potential development of a German atomic bomb. The letter contributed to the establishment of the Manhattan Project and the development of an atomic bomb by the United States. On August 6 and 9, 1945, the US dropped two atomic bombs on the Japanese cities of Nagasaki and Hiroshima, killing around 220,000 people. After the war, Einstein came to regret his cooperation deeply and is reported to having said: "If I had known that the Germans would not succeed in constructing the atom bomb, I would never have lifted a finger" (Jungk 1956: p. 87). But, would it be fair to hold Einstein responsible for the dropping of two atomic bombs and the killing of so many people? Or, would it even be fair to hold him responsible for the development of the atomic bomb, or even for signing the letter? Given his knowledge of the developments at that time, it was perhaps the most reasonable thing to do.

In order to fairly attribute responsibility to an agent, a number of conditions need to be met. The following five conditions are usually mentioned when responsibilityas-blameworthiness is discussed (Van de Poel et al. 2015: pp. 21-23):

1. The agent is a moral agent, which implies that the agent can act intentionally, has deliberative capacities (reason-responsiveness);

\footnotetext{
6 Nevertheless, attributing blame or liability may serve other aims such as retribution, or doing justice to victims (rather than encouraging responsible innovation). Therefore, sometimes it may be appropriate to allocate blame or liability even if it discourages responsible innovation. Here, however, we take the perspective what responsibilities should be attributed in the light of responsible innovation. The other aims of attributing responsibility are further discussed below.
} 
2. There is a causal connection between the (actions of the) agent and the object (action, outcome, character trait) the agent is held responsible for;

3. The agent has done something wrong (in order to be blameworthy);

4. The agent has been in a relevant sense free (e.g. absence of coercion);

5. The agent knew that she did something wrong or produced undesirable consequences.

Two aspects regarding this set of conditions are noteworthy. First, the conditions can be further specified in a host of ways. In other words, more specific accounts of each criterion can be established. For the present purpose, the outline of these conditions provides a sufficient conceptual framework for the fair attribution of responsibility.

Second, these are primarily conditions for responsibility-as-blameworthiness. For other types of responsibility, additional conditions may apply or the conditions need to be reformulated. Nevertheless, also for these other types of responsibility, the previously listed conditions are relevant (Van de Poel et al. 2015: chapter 1). This is, for instance, the case for forward-looking obligation-responsibility. The attribution of forward-looking obligation-responsibility is fair, if an agent is a moral agent (condition 1), is able to make a causal contribution to the event, she is responsible for (condition 2), has insight into the normative implications of her act (condition 3 and 5), is free to act (condition 4) and knows the (possible) consequences of her action (condition 5).

Outlining the five conditions is helpful to understand the problem of fairly attributing responsibility to innovators, in particular with regard to the social consequences of innovations. Apart from the first condition of moral agency, each of the four remaining conditions are disputable in the context of innovation, as we will argue (see also Swierstra and Jelsma 2006).

The causal condition for responsibility is rarely met in innovation as a multiplicity of actors is involved and there are long causal chains between the innovation process and the eventual social impacts. Outcomes are affected by actions of a variety of actors and it may be hard, if not impossible, to detect a causal connection between the actions of individual innovators and the overall consequences of innovation processes. Innovation involves great uncertainty (Hansson 1996). In terms of forward-looking responsibility, innovators lack the control to make a causal difference in terms of the outcomes of innovation.

While there are clear instances of wrong-doing in engineering and innovation, what is morally desirable or acceptable in this context is often disputable, dilemmatic or underdetermined. Innovations are typically addressed by a range of conflicting requirements and moral standards. Therefore, in many cases compromises or tradeoffs between moral values are inevitable (Van de Poel 2009).

Also, the freedom condition can be undermined in innovation in various ways. For one thing, individual innovators often work in companies or large research organizations, which constrain their freedom through corporate statutes and other measures of internal regulation. Moreover, if the freedom condition is understood in terms of the availability of options to the agent to avoid undesirable outcomes, it may be even harder to fulfill. This is because of the causal inefficiency of individual agents in such settings, as mentioned before. 
The knowledge condition is also rarely met in innovation. Innovating involves many uncertainties and unknowns. The social consequences of an innovation may not only be unforeseen but in principle be unforeseeable. According to Grinbaum and Groves, this means that whether the actions of innovators will have good or bad consequences will often depend on luck, which undermines the attribution of responsibility. As they write: "[T]here is no guarantee that moral luck in the uncertain future will not mean that one's efforts to act responsibly will not turn out to have unintended consequences. Whatever choices are made, the final verdict on a distinction between responsible and irresponsible innovation is not in our capacity to make" (Grinbaum and Groves 2013: p. 139).

Not only can there be reasonable disagreement about innovations' desirability once they have been implemented (as pointed out above), also their impacts cannot be fully anticipated beforehand. How can innovators ever decide which innovative pathway is responsible and should be pursued? This seems to undermine the central idea of responsible innovation.

In addition, it seems that taken together these individual issues give rise to another even profounder problem. The well-known Collingridge dilemma (Collingridge 1980) with respect to technological development postulates that in the early phases of innovation innovations are usually still malleable (so the freedom condition is met) but the social consequences are often unknown (the knowledge condition is not met). In later phases, when it becomes possible to fulfill the knowledge condition, technology has become so deeply entrenched with society that it will be hard to shape it, which undermines compliance with the freedom condition. While there are ways to deal with the Collingridge dilemma (Collingridge 1992; Genus and Stirling 2018; Van de Poel 2017), taken together the problems outlined before clearly indicate the difficulty of fulfilling the conditions for fairly attributing responsibility to innovators.

\subsection{Is it effective to attribute these responsibilities to innovators?}

It has been doubted whether the attribution of responsibility to innovators morally improves technological development. These doubts prevail especially regarding the attribution of (legal) liability and of (moral) blameworthiness.

There are a number of cases from engineering ethics that suggest that legal liability is (at least sometimes) detrimental to the willingness of engineers, or innovators, to take responsibility. An example is the TV Antenna Tower Collapse case study, a partial fictional case study that is nevertheless based on a real case (Texas A\&M University 1992). In this case, engineers from the company Antenna Engineering have designed a FM antenna tower, including a plan for the construction of the tower that has been approved by a local company, Riggers, which is appointed to build the tower. However, during the actual construction, Riggers runs into an unexpected problem that makes it impossible to follow the original construction plan. They devise an alternative plan without consulting an engineer and ask Antenna Engineering for their advice. However, Antenna Engineering refuses to give advice out of fear of legal liability. Indeed, Riggers' plan turns out to be inadequate and the tower collapses during the final phase of construction, killing 5 technicians. 
Another example is the DC-10. On March 3, 1974, a DC-10 crashed just outside Paris killing all 346 people on board (Eddy et al. 1976; Fielder and Birsch 1992). The cause turned out to be a cargo door that had opened. The problem with the cargo doors was known; Applegate, an engineer at Convair, a subcontractor of McDonnell Douglas, had written a memorandum about it. Most likely also other engineers at Convair and McDonnell Douglas were aware of the problem. Convair was not allowed to share this knowledge with the Federation Aviation Agency (FAA), because of contractual obligations towards McDonnell Douglas. Moreover, Convair did not bring the problem formally to McDonnell Douglas' attention, allegedly because they were more likely to be liable for the costs of correcting it if they revealed the problem. While several people knew about the issue, no actions were undertaken to solve it.

In both cases, we see that a fear of legal liability discouraged the assuming of forward-looking responsibility to prevent possible harm. In both cases, the accident would have been prevented if the companies involved and the engineers working for these companies, had assumed such forward-looking responsibility. In fact, in both cases it can be argued that the engineers and their companies should have taken forward-looking responsibility and are morally blameworthy for omission, despite their justified fear of legal liability.

Nevertheless, both cases illustrate a more general point, namely that responsibility attributions affect behavior. Often when allocating responsibility these effects are intended (although we also attribute responsibility for other reasons); but we should be aware that responsibility attributions can also have counterproductive behavioral effects. Indeed, the attribution of responsibility fulfills different functions, which are contrary at times (Eshleman 2016; Doorn 2012; Cane 2002). The merit-based perspective on responsibility attributions, for instance, understands responsibility as an articulation of what people morally deserve and stresses notions like blame and guilt, but also praise (e.g. Strawson 1962; Wallace 1994; Fischer and Ravizza 1998). The consequentialist perspective sees responsibility attributions mainly as a means to change people's behavior for the better (e.g. Schlick 1962). In addition to these two more common perspectives, we may add a third that understands the attribution of responsibility as a means to do justice to victims (Zandvoort 2005). These three perspectives may result in conflicting attributions of responsibility.

\section{Disentangling the varieties of responsibility in responsible research}

In the following, we will propose three strategies to deal with the previously outlined problems. We will show how an improved understanding of the conceptual issues of responsible innovation supports their overcoming and the realization of their nature as pseudo-problems. We will sharpen the reasoning about responsibility in innovation in three related ways. First, we will outline why it is important to employ the distinction between holding responsible and taking responsibility that has been suggested before in the literature on responsibility. Second, we encourage more precision about what it is exactly that innovators are responsible for. Third, we will argue that the purpose of responsibility attributions in responsible innovation and their effects for practice should be revealed and critically taken into account. 


\subsection{Supererogatory responsibility: holding responsible versus taking responsibility}

When we discuss under what conditions it is fair to attribute responsibility to a certain agent, we usually think of the activity of holding someone responsible for something. These situations may be formalized as follows:

Agent $\mathrm{j}$ holds agent $\mathrm{i}$ responsible for $\varphi$

In this proposition, we suggest $\mathrm{i}$ and $\mathrm{j}$ to refer to different moral agents and $\varphi$ to an action (or omission), outcome or character trait. Holding responsible can mean different things depending on what type of responsibility we are focusing on. For backward-looking responsibility, holding responsible might mean holding someone accountable (in the sense of being obliged to account for one's actions and their outcomes), blaming someone (as in the case of blameworthiness) or holding someone liable in the sense of being morally or legally obliged to compensate for damage that occurred. In the case of forward-looking responsibility, it may mean allocating responsibility to someone, or-in more formal (organizational) settings-delegating responsibility.

What is typical for all these situations is the existence of another agent $j$ that ascribes responsibility to agent $i$, which naturally raises the question whether such attribution is fair. This is different in the case of taking responsibility for some $\varphi$ as the voluntary act of an agent $i$. Nevertheless, there is a pendant to the fairness issue in the realm of 'taking responsibility'. Obviously, there are events for which an agent cannot reasonably take responsibility, for example, because she is unable to affect them. The five conditions for holding someone responsible in a fair manner are equally relevant when assessing whether it is reasonable for someone to take responsibility. Nevertheless, there is an important difference. There is more room for reasonably taking responsibility than there would be for someone else attributing the same responsibility in a fair way. In other words, for some $\varphi$ for which it may be unfair to hold an agent i responsible, that same agent i may still reasonably take responsibility.

An example is the earlier, briefly discussed case of Albert Einstein. By later regretting his decision to sign, Einstein took responsibility, both in terms of moral ownership of his earlier decision as well in terms of a willingness to account for his earlier actions. ${ }^{7}$ He also accepted a certain degree of blame. Nevertheless, it would seem unfair for others to hold him morally accountable and certainly moral blameworthy for his earlier decision and some of the consequences along the causal chain (like the dropping of two atomic bombs on Japan).

We usually consider it morally praiseworthy when people take responsibility in this type of situations. Such acts of taking responsibility are morally supererogatory, i.e. they are not morally required, but if agents take responsibility for them it is morally

\footnotetext{
7 Susan Wolf suggests that such behavior exemplarily displays a virtue that has similarities with generosity: "[This virtue] involves an expectation and a willingness to be held accountable for what one does, understanding the scope of 'what one does,' particularly when costs are involved, in an expansive rather than a narrow way. It is the virtue that would lead one to offer to pay for the vase that one broke even if one's fault in the incident was uncertain; the virtue that would lead one to apologize, rather than get defensive, if one unwittingly offended someone or hurt him. Perhaps this virtue is a piece or an aspect of a larger one which involves taking responsibility not just for one's actions and their consequences, but for a larger range of circumstances that fall broadly within one's reach" (Wolf 2001, p. 13).
} 
praiseworthy. This also suggests an association of the taking of responsibility and the possession of certain virtues. In fact, as we have argued before, responsibility itself may be seen as a kind of virtue that is associated with the assuming, or taking, of specific backward-looking and forward-looking responsibilities.

Once we recognize the existence of supererogatory responsibilities, it becomes clear that the question to ask is not: what responsibilities can be fairly attributed to innovators, but rather what responsibilities can innovators reasonably or rationally assume? In fact, most of the arguments that have been levelled against the fairness of attributing responsibility to innovators do not make it impossible or irrational for innovators to assume certain responsibilities (see also Davis 2012). This is certainly not the case, if we are simultaneously more precise about what innovators should take responsibility for, as we will do in the next section.

\subsection{Responsible for what?}

If we focus on the activity of taking responsibility, this may be described as:

i takes responsibility for $\varphi$

Where i refers to a moral agent and $\varphi$ to an action (or omission), outcome or character trait. One way to make responsibility attributions in responsible innovations less prone to the two problems, we have outlined before is by being more precise about what $\varphi$ is or could reasonably be in the context of responsible innovation.

It should be noted that authors who have pointed out the problem of fairly attributing responsibility to innovators (as discussed above), often implicitly or explicitly seem to think of $\varphi$ as the eventual societal consequences of innovation (for example the dropping of two atomic bombs on Japan in the earlier discussed case of Einstein). In the light of responsible innovation, this seems sensible. As we have seen, one of the most general definitions of responsible innovation understands it as an "on-going process of aligning research and innovation to the values, needs and expectations of society." Given this definition, it seems reasonable to understand $\varphi$ as the product of an innovation process and evaluate, whether it lives up to the needs and expectations of society and whether societal values have been respected in terms of the social consequences of innovation.

However, this narrow understanding of responsible innovation comes at a cost. Because of the uncertainties involved in innovation processes, it is impossible to distinguish responsible from irresponsible innovation during the innovation process itself, as suggested by Grinbaum and Groves. This means that responsible innovation cannot be an action-guiding doctrine for those involved in innovation.

It should be noted that this problem is not entirely unique to this specific understanding of responsible innovation. In fact, it is a problem that is common to certain consequentialist ethical theories that try to define right actions in terms of the actual outcome of these actions (and the goodness of these outcomes). Since the actual outcomes of action are in many cases, and certainly in the case of innovation, uncertain, such consequentialist theories cannot be action-guiding (Lenman 2000). A possible solution is not to define rightness of actions in terms of the actual outcomes (and their goodness) but rather in terms of (reasonably) expectable outcomes (Cowen 2006). 
Although such strategy is also possible in the case of responsible innovation, our proposal is to follow another strategy, namely to understand $\varphi$ in terms of intermediate outcomes of innovation rather than in terms of the eventual social consequences of innovations. This is also suggested by the earlier introduced matrix of responsibility in responsible innovation. The matrix indicates that innovators have a responsibility for the process of innovation and the outcomes of innovations in terms of the developed innovative products (or services or systems).

Both the process as well as the products of innovation are best subsumed under the umbrella term 'outcomes' for which an innovator may be responsible. For the innovative products that result from the innovation process this is straightforward. However, also the process of innovation is best understood as an outcome (rather than as an action). The innovation process is the emergent outcome of the actions of many agents, and, hence, the actions of innovators and the resulting innovation process remain clearly distinct.

If we understand $\varphi$ in this way, fulfilling some of the conditions for fairly attributing responsibility to innovators become less problematic, particularly if we recognize that there are supererogatory responsibilities, which can be taken by innovators rather than being attributed to them by others.

In the literature on responsible innovations, normative definitions both in terms of process and products are available that make it easier to define wrong-doing, or-for the case of forward-looking responsibility - to distinguish morally desirable actions and outcomes from undesirable ones. For example, as indicated before a responsible innovation process according to the literature needs to meet the conditions of anticipation, reflexivity, inclusiveness (or deliberation) and responsiveness. In terms of the products of innovation, it may for example be postulated-in line with the definition of van den Hoven - that these should embed relevant values as far as feasible. This may then translate in more specific (forward-looking) responsibilities, for example to translate values into design requirements and to search for innovative designs that meet as many values as possible simultaneously.

In addition, the freedom and knowledge condition are easier to meet if $\varphi$ is defined in terms of the process or product dimension of responsible innovation rather than in terms of societal outcomes. Obviously, innovators have more control over, and usually also more freedom of action with respect to the process and direct outcomes of innovation compared to societal consequences. They will usually also have more knowledge how their own actions will affect the process of innovation and its products compared to eventual societal consequences.

The causal condition may also be more easily met as usually less agents are directly causally involved in the innovation process than in bringing about the social consequences of innovation and also the causal chains are shorter. Still, causality remains an issue because of the multiplicity of agents involved. For example, none of the agents in isolation may be causally effective with respect to making the innovation process inclusive. ${ }^{8}$ If the process is not inclusive, it is hard, if not impossible, to hold any of the individual agents (fully) responsible (as-blameworthy) for the lack of inclusiveness

\footnotetext{
8 There are obviously other societal and political actors, powerful enough to affect innovation processes in such desirable directions. Innovators are not the only group of societal agents that carry a responsibility for shaping these dynamics (Sand 2018). Moreover, there are certainly political measures to support innovators'
} 
Table 3 Functions or aims of responsibility attributions

\begin{tabular}{ll}
\hline Meaning of responsibility & Aim of attributing responsibility \\
\hline Backward-looking & \\
Responsibility-as-blameworthiness & Retribution \\
Responsibility-as-accountability & Maintaining moral community \\
Responsibility-as-liability & Remediation, justice to victims \\
Forward-looking & \\
Responsibility-as-obligation & Efficacy \\
Responsibility-as-virtue & Due care to others \\
\hline
\end{tabular}

of the innovation process. Nevertheless, it will often remain rational for innovators to take responsibility, as their causal role or causal efficacy is often not given but they can make deliberate attempts to increase their causal powers as part of taking responsibility.

Another strategy in such cases may be to redefine $\varphi$ not in terms of the overall process or products of innovation but in still more intermediate terms. What this strategy suggests is that the earlier presented argument about the unfairness of attributing responsibility to innovators applies to certain $\varphi$, but not to other ones. If we make $\varphi$ specific enough, there are always relevant responsibilities that innovators can rationally take. To sum up, the earlier presented argument of the unfairness of attributing responsibility to innovators is valid, if $\varphi$ is defined in terms of eventual societal outcomes, but for most innovation processes it is possible to define more specific $\varphi$ in terms of intermediate outcomes of innovation processes for which it is possible to hold innovators fairly responsible, or for which innovators can reasonably take responsibility.

\subsection{What types of responsibility are most important for responsible innovation?}

As we have seen before, attributions of responsibility may have different functions (moral desert, behavior change, justice to victims) following contrary and conflicting purposes. These tensions can be resolved by acknowledging the different types of responsibility and their respective functions. We should ask: What functions are most important in the light of responsible innovation?

As suggested in van de Poel et al. (2015: pp. 18-20), the attribution of different types of responsibility may serve different functions or goals. This is outlined in Table 3 .

Below, we will discuss for each type of responsibility which functions it may serve and how important these functions are in responsible innovation.

The first type of (backward-looking) responsibility is accountability. The act of holding someone accountable, or taking accountability, confirms the moral agency of the accountable agent and the moral ownership of the acts or outcomes for which the agent is (held) accountable. In addition, accountability may also be seen as the confir-

Footnote 8 continued

assuming virtue-responsibilities as we describe below. However, we believe that all distinctions regarding the concept of responsibility introduced above will apply to those actors as well as many of the limitations of attributing ordinary backward-looking responsibilities. 
mation of certain moral rules and the existence of a moral community of agents who are willing to account for their actions in the light of shared moral rules (Kutz 2000). In the light of responsible innovation, accountability may therefore be particularly important in confirming the (moral) trustworthiness of innovators and confirming, or restoring public trust in innovators and innovation. Here, it is important that innovators are not the only accountable party in this process. The general public is equally a potential addressee, which opens the innovation process to a wider range of concerns and values through accountability (Genus and Stirling 2018).

In addition, accountability may serve another important function in responsible innovation. If something has gone wrong or an innovation has failed, accountability may not only be a first step in restoring trust but also in learning from one's mistakes. By accounting for what happened, it might become clearer to innovators what exactly has gone wrong and how to learn from that to prevent future failure. Also, for this reason, the attribution of accountability to innovators seems crucial in responsible innovation.

The second type of responsibility to consider is blameworthiness. The attribution of this type of responsibility serves the goal of retribution. Retribution may indeed sometimes be appropriate in cases of severe moral wrongdoing that result in largescale harm. In such cases, it may be argued that some form of blameworthiness is also instrumental in restoring public trust. Although such cases certainly occur in innovation, they seem to be rather exceptional. Moreover, the emphasis on blameworthiness may have detrimental behavioral effects and discourage the taking of forward-looking responsibility, as argued before. This is not to say that blame is never appropriate but blameworthiness should be handled with care in responsible innovation.

The final type of backward-looking responsibility to consider is liability. One of the important functions of liability is to do justice to victims. Liability can imply an obligation to compensate victims for damages. Moreover, its proponents believe that the threat of liability discourages reckless or negligent behavior (Zandvoort 2005). However, as we have seen, the positive behavioral effects of liability are at least debatable. The examples of the Antenna Tower and DC-10 have shown how liability has discouraged responsible behavior and thus contributed to the occurrence of serious accidents rather than to their prevention. Nevertheless, it would seem that the goal of liability attributions, doing justice to victims, is relevant and important for responsible innovation.

The question that needs to be asked is whether this goal should be achieved by the attribution of liability. Can it also, and perhaps better so, be achieved in other ways, for example through some form of collective insurance for the risks and dangers of innovation? Answering this question in detail is beyond the scope of this paper. Nevertheless, we can conclude that we should carefully evaluate such arrangements for their effects on the willingness of innovators to take other relevant kinds of responsibility.

When it comes to forward-looking responsibility, both responsibility-as-obligation and responsibility-as-virtue are important in the light of responsible innovation. Obligation-responsibility may be understood as the obligation to see to it that a certain desirable state-of-affairs occurs and the function of attributing such responsibilities is effectiveness in bringing about such state-of-affairs. In the most abstract terms, the desirable state-of-affairs for responsible innovation may be formulated as avoiding harm and realizing good. However, as we have seen it may be desirable to formulate 
the relevant $\varphi$ in more concrete and intermediate terms, for example in terms of the process requirements for responsible innovation (anticipation, reflexivity, inclusiveness and responsiveness) or in terms of products that embed relevant moral values. In some cases, even more specific state-of-affair-definitions may be required in order to be able to fairly allocate such obligation-responsibilities to innovators. At the same time, it is hard, if not impossible, to fully define what should be done to fulfill such responsibilities. It may even be the case that in the course of time, new insights arise (through moral learning) about what state-of-affairs are desirable to achieve (Van de Poel 2018).

Responsible innovation thus has an open-ended character in which learning along the way is crucial (Genus and Stirling 2018). The attribution of (forward-looking) responsibilities should be attuned to this open character (Adam and Groves 2011). Since obligation responsibilities have a discretionary component (Goodin 1995), they can accommodate the openness of responsible innovation at least to some extent. In addition, however, responsibility-as-virtue is required, which implies an openness to a diversity of normative demands.

Virtue-responsibility is therefore particularly important for responsible innovation. It suggests a willingness to take (other types of) responsibilities, also in cases in which it may perhaps not be fair to allocate such responsibilities to the agent concerned. As we have shown, taking responsibility may be particularly important in uncertain settings, such as innovation processes.

Responsibility-as-virtue is associated with due care to others, which seems to be an important motivation behind responsible innovation. In fact, many authors refer in their definition to such understanding of responsible innovation as "taking care of the future through collective stewardship of science and innovation in the present" (Stilgoe et al. 2013: p. 1570). Although several authors discuss care as a key virtue in the context of innovation processes (Grinbaum and Groves 2013, p. 134), there are other important forward-looking virtues that can be proactively assumed by an agent such as generosity, rigor, eagerness and creativity (Wolf 2001, p. 14; Sand 2018).

\section{Conclusions}

We have argued that two types of responsibility are particularly important in relation to responsible innovation, namely accountability and responsibility-as-virtue. Accountability is crucial for two reasons. First, it does not only confirm the moral authorship of innovators but also the existence of a set of shared moral rules and a moral community - including the public — around innovation; it is therefore important for moral trust in innovators and to make innovation more responsive to the needs, values and expectations of society. In addition, accountability is crucial if something has gone wrong, when accidents occur or undesirable consequences materialize. In such cases, accountability is a first step in (incremental) learning, which is crucial for responsible innovation.

Responsibility-as-virtue is also crucial for responsible innovation for a number of reasons. First, it comes with a willingness to take on a number of more specific responsibilities. As we have seen even in situations in which it may be unfair to exter- 
nally ascribe certain specific responsibilities to innovators, innovators can take such responsibilities actively and voluntary and it is virtuous if they do so. In this way, responsibility-as-virtue also serves the goal of due care to others, which is suggested by many participants in this debate to be an important underlying aim of responsible innovation. How can such responsibility-as-virtue become common without necessarily holding innovators in a backward-looking way responsible? We think that by discussing admirable examples in public and in teaching engineering ethics as we suggested through the previously mentioned case of Albert Einstein, the voluntary taking of responsibility can be encouraged.

Virtue-responsibility also stresses the open-ended character of responsibility in innovation. Due to uncertainty and complexity, it is often impossible to know beforehand which action would be the most responsible. In other words, new normative demands may arise during the innovation process and agents need to recognize and respond to such normative demands. Agents who are responsible in the virtue sense possess this skill.

In addition, the three other types of responsibility we have distinguished, obligationresponsibility, blame-responsibility and liability play a minor role in responsible innovation. Each of them is occasionally appropriate, depending on how $\varphi$ for which innovators are responsible is exactly defined.

We can conclude that the three strategies proposed help to overcome some of the problems of attributing responsibility to innovators. We do not deny that dealing with the sketched problems may eventually also require institutional changes and the deliberate organization of responsibility in innovation. Discussing such proposals is beyond the scope of this paper. However, being more precise about the notion of responsibility in innovation, as proposed in this contribution, is a prerequisite for adequate institutional change. Shortsighted attempts to attribute responsibility to innovators may well have detrimental effects. ${ }^{9}$

Acknowledgements This study was generously funded with a research travel grant by the Karlsruhe House of Young Scientists (KHYS) at the Karlsruhe Institute of Technology.

Open Access This article is distributed under the terms of the Creative Commons Attribution 4.0 International License (http://creativecommons.org/licenses/by/4.0/), which permits unrestricted use, distribution, and reproduction in any medium, provided you give appropriate credit to the original author(s) and the source, provide a link to the Creative Commons license, and indicate if changes were made.

\section{References}

Adam, B., \& Groves, C. (2011). Futures tended: Care and future-oriented responsibility. Bulletin of Science, Technology \& Society, 31(1), 17-27. https://doi.org/10.1177/0270467610391237.

Andre, J. (1983). Nagel, williams, and moral luck. Analysis, 43(4), 202-207. https://doi.org/10.2307/3327 571.

Cane, P. (2002). Responsibility in law and morality. Oxford: Hart Publishing.

Collingridge, D. (1980). The social control of technology. London: Frances Pinter.

\footnotetext{
9 We are extremely grateful for the critical comments of two unknown reviewers, who helped us to sharpen our arguments. This research was conducted during a research visit of Martin Sand at the Department of Values, Technology and Innovation (TU Delft) early 2018.
} 
Collingridge, D. (1992). The management of scale. Big organizations, big decisions, big mistakes. London and New York: Routledge.

Cowen, T. (2006). The epistemic problem does not refute consequentialism. Utilitas, 18(4), 383-399. https://doi.org/10.1017/S0953820806002172.

Davis, M. (2012). "Ain't no one here but us social forces": Constructing the professional responsibility of engineers. Science and Engineering Ethics, 18(1), 13-34. https://doi.org/10.1007/s11948-010-9225-3.

Directorate-General for Research and Innovation EU. (2013). Options for strengthening responsible research and innovation report of the expert group on the state of art in Europe on responsible research and innovation. Brussel: European Commission.

Doorn, N. (2012). Responsibility ascriptions in technology development and engineering: Three perspectives. Science and Engineering Ethics, 18(1), 69-90. https://doi.org/10.1007/s11948-009-9189-3.

Eddy, P., Potter, E., \& Page, B. (1976). Destination disaster: From thetri-motor to the DC-10, the risk of flying. New York: Quadrangle.

Eshleman, A. (2016). Moral responsibility. In E. N. Zalta (Ed.), The Stanford encyclopedia of philosophy (Winter 2016 Edition).

European Commission. (2012). Responsible Research and Innovation. Europe's ability to respond to societal challenges. London: E. Union.

European Commission. (2014). Rome declaration on responsible research and innovation in Europe. https://ec.europa.eu/research/swafs/pdf/rome_declaration_RRI_final_21_November.pdf. Accessed 21 January 2017.

European Commission. (2017). Responsible research \& innovation. https://ec.europa.eu/programmes/hor izon2020/en/h2020-section/responsible-research-innovation. Accessed 21 January 2017.

Fielder, J. H., \& Birsch, D. (1992). The DC-10 case: A study in applied ethics, technology, and society (SUNY series, case studies in applied ethics, technology, and society). Albany: State University of New York Press.

Fischer, J. M., \& Ravizza, M. (1998). Responsibility and control: A theory of moral responsibility (Cambridge studies in philosophy and law). Cambridge: Cambridge University Press.

Genus, A., \& Stirling, A. (2018). Collingridge and the dilemma of control: Towards responsible and accountable innovation. Research Policy, 47(1), 61-69. https://doi.org/10.1016/j.respol.2017.09.012.

Goodin, R. E. (1995). Utilitarianism as a public philosophy. Cambridge: Cambridge University Press.

Grinbaum, A., \& Groves, C. (2013). What is "responisble" about responsible innovation? Understanding the ethical issues. In R. Owen, J. Bessant, \& M. Heintz (Eds.), Responsible innovation (pp. 119-142). Chistester: Wiley.

Hansson, S. O. (1996). Decision making under great uncertainty. Philosophy of the Social Sciences, 26(3), 369-386. https://doi.org/10.1177/004839319602600304.

Hart, H. L. A. (1968). Punishment and responsibility: Essays in the philosophy of law. Oxford: Clarendon Press.

Jungk, R. (1956). Brighter than a thousand Suns. London: Penquin Books.

Kutz, C. (2000). Complicity: Ethics and law for a collective age (Cambridge studies in philosophy and law). Cambridge; New York: Cambridge University Press.

Lenman, J. (2000). Consequentialism and cluelessness. Philosophy \& Public Affairs, 29(4), 342-370.

Owen, R., Stilgoe, J., Macnaghten, P., Gorman, M., Fisher, E., \& Guston, D. (2013). A framework for responsible innovation. In R. Owen, J. Bessant, \& M. Heintz (Eds.), Responsible innovation (pp. 27-50). Chichester: Wiley.

Pellé, S., \& Reber, B. (2015). Responsible innovation in the light of moral responsibility. Journal on Chain and Network Science, 15(2), 107-117. https://doi.org/10.3920/JCNS2014.x017.

Sand, M. (2018). The virtues and vices of innovators. Philosophy of Management, 17(1), 79-95. https:// doi.org/10.1007/s40926-017-0055-0.

Schlick, M. (1962). When is a man responible? In D. Rybib (Ed.), Problems of ethics (pp. 143-158). New York: Dover.

Smith, A. M. (2007). On being responsible and holding responsible. The Journal of Ethics, 11(4), 465-484. https://doi.org/10.1007/s10892-005-7989-5.

Stilgoe, J., Owen, R., \& Macnaghten, P. (2013). Developing a framework for responsible innovation. Research Policy, 42(9), 1568-1580. https://doi.org/10.1016/j.respol.2013.05.008.

Strawson, P. (1962). Freedom and resentment. Proceedings of the British Academy, 48, 187-211.

Swierstra, T., \& Jelsma, J. (2006). Responsibility without moralism in techno-scienctific design practice. Science, Technology and Human Values, 31(3), 309-332. 
Texas A\&M University. (1992). TV antenna collapse. http://www.onlineethics.org/File.aspx?id=45810. Accessed 10 Jan 2018.

Van de Poel, I. (2009). Values in engineering design. In A. Meijers (Ed.), Handbook of the philosophy of science (Vol. 9, pp. 973-1006)., Philosophy of technology and engineering sciences Oxford: Elsevier.

Van de Poel, I. (2017). Society as a laboratory to experiment with new technologies. In D. M. Bowman, E. Stokes, \& A. Rip (Eds.), Embedding new technologies into society: A regulatory, ethical and societal perspective (pp. 61-87). Singapore: Pan Stanford Publishing.

Van de Poel, I. (2018). Moral experimentation with new technology. In I. Van de Poel, D. C. Mehos, \& L. Asveld (Eds.), New perspectives on technology in society: Experimentation beyond the laboratory (pp. 59-79). Oxon and New York: Routledge.

Van de Poel, I., Royakkers, L., \& Zwart, S. D. (2015). Moral responsibility and the problem of many hands. Oxon and New York: Routledge.

Van den Hoven, J. (2013). Value sensitive design and responsible innovation. In R. Owen, J. Bessant, \& M. Heintz (Eds.), Responsible innovation (pp. 75-84). Chichester: Wiley.

Van den Hoven, J., Lokhorst, G.-J., \& Van de Poel, I. (2012). Engineering and the problem of moral overload. Science and Engineering Ethics, 18(1), 143-155. https://doi.org/10.1007/s11948-011-9277-z.

Van Gorp, A. (2005). Ethical issues in engineering design. Safety and sustainability., Simon Stevin Series in the Philosophy of Technology Delft: TU Delft.

Vargas, M. (2013). Building better beings: A theory of moral responsibility. Oxford: Oxford University Press.

Vincent, N. A. (2011). A structured taxonomy of responsibility concepts. In N. A. Vincent, I. van de Poel, \& J. van den Hoven (Eds.), Moral responsibility: Beyond free will and determinism (pp. 15-35). Dordrecht: Springer.

Von Schomberg, R. (2012). Prospects for Technology Assessment in a framework of responsible research and innovation. In M. Dusseldorp \& R. Beecroft (Eds.), Technikfolgen abschätzen lehren: Bildungspotenziale transdisziplinärer Methoden (pp. 39-61). Wiesbaden: Springer.

Wallace, R. J. (1994). Responsibility and the moral sentiments. Cambridge, MA: Harvard University Press.

Watson, G. (2004a). Reasons and responsibility. Agency and answerability: Selected essays (pp. 289-317). New York: Oxford University Press.

Watson, G. (2004b). Two faces of responsibility. Agency and answerability: Selected essays (pp. 260-288). New York: Oxford University Press.

Williams, G. (2008). Responsibility as a virtue. Ethical Theory and Moral Practice, 11(4), 455-470.

Wolf, S. (2001). The moral of moral luck. Philosophical Exchange, 31(1), 1-19.

Zandvoort, H. (2005). Knowledge, risk, and liability: Analysis of a discussion continuing within science and technology. In A. J. M. Peijnenburg, R. Festa, \& A. Aliseda (Eds.), Cognitive structures in scientific inquiry: Essays in debate with Theo Kuipers (Vol. 2, pp. 469-501)., Vol. Poznań studies in the philosophy of the sciences and the humanities Amsterdam/New York: Rodopi. 